\title{
Body size and abnormal lipids among adult patients at the Baptist Medical centre, Ogbomoso, Nigeria
}

\author{
*Amole $\mathrm{OI}^{1}$, OlaOlorun $\mathrm{DA}^{1}$, Odeigah $\mathrm{OL}^{2}$
}

1. Department of Family Medicine, Bowen University Teaching Hospital

2. Department of Family Medicine, University of Ilorin Teaching Hospital, Ilorin, Kwara State

\begin{abstract}
Background: In many developing countries overweight, obesity and obesity-related morbidity are becoming a problem of increasing importance. Obese individuals are more likely to have elevated total cholesterol, triglycerides, low density lipoprotein (LDL) cholesterol and decreased high density lipoprotein (HDL) cholesterol.

Objective: To determine the prevalence of obesity using the measure of body mass index (BMI) and abnormal lipid level and the association between obesity and abnormal lipid level among adults in Ogbomoso, Nigeria.

Methods: A cross-sectional descriptive study of 400 adults aged 18 years and above was carried out at the Baptist Medical Centre, Ogbomoso, Nigeria. Participants were administered a standardized questionnaire and had measurements of weight, height and blood lipids taken.

Results: Four hundred subjects were randomly selected (221 females and 179 males) with a mean age of $48.65 \pm 16.56$ years. The overall prevalence of obesity was $14.75 \%$ (8.9\% for males and $19.5 \%$ for females $\mathrm{p}<0.05)$. The female subjects were significantly more sedentary than the males $(50.8 \%$ for males, $62.4 \%$ for females, $\mathrm{p}<0.05)$. Most of the subjects who were obese (88.1\%) preferred high calorie food. The overall prevalence of abnormal lipid levels was $28.5 \%$ (26.8\% for males and $29.9 \%$ for females). The prevalence of abnormal lipid levels among the subjects who were obese was $40.7 \%$.

Conclusion: Obesity in this environment is particularly significant among females and is associated with abnormal lipid level.

Key words: Obesity, blood lipid level, body mass index.

African Health Sciences 2013; 13(1): 32 - 37 http://dx.doi.org/10.4314/ahs.v13i1.5
\end{abstract}

\section{Introduction}

In many developing countries overweight, obesity and obesity-related morbidity are becoming a problem of increasing importance. ${ }^{1}$ Urbanization and economic development has led to a nutritional transition characterized by a shift to a higher caloric content of diet and/or to the reduction of physical activity, and whose consequences are changes in the body composition of the individuals. ${ }^{1}$ About 1.2 billion people (approximately $20 \%$ of the world population) in the world are overweight and at least 300 million of them are obese. ${ }^{2}$ The World Health Organization (WHO) projects that by 2015,

\author{
*Corresponding author: \\ Isaac Olusayo Amole \\ Department of Family Medicine \\ Bowen University Teaching Hospital \\ P. O. Box 15 \\ Ogbomoso, Oyo State \\ Nigeria \\ Nigeria. E-mail: amoleio@yahoo.com
}

worldwide, approximately 2.3 billion adults will be overweight and more than 700 million will be obese. ${ }^{3}$ Obesity is defined as a condition of abnormal or excessive fat accumulation in the adipose tissue of the body.4 Body mass index (BMI), defined as the weight in kilogrammes divided by the square of height in metres $(\mathrm{kg} / \mathrm{m} 2)$ is used to measure the "degree of fatness". Overweight is defined as BMI values between 25 and $29.9 \mathrm{~kg} / \mathrm{m}^{2}$ while obesity is BMI value $>30 \mathrm{~kg} / \mathrm{m}^{2}$.4Normal weight is characterized by a BMI of between 18 and 24.9 $\mathrm{kg} / \mathrm{m}^{2}$.

Obese individuals are more likely to have elevated total cholesterol, triglycerides, low density lipoprotein (LDL) cholesterol and decreased high density lipoprotein (HDL) cholesterol. ${ }^{4,5}$ This metabolic profile is most often seen in obese people with a high accumulation of intra-abdominal fat and has consistently been related to an increased risk of coronary heart disease (CHD). ${ }^{4}$ With weight loss, the levels of triglycerides can be expected to improve. 
A $10 \mathrm{~kg}$ weight loss can produce a 15\% decrease in LDL cholesterol levels and an $8 \%$ increase in HDL cholesterol ${ }^{4}$. High Density Lipoprotein cholesterol reduces the risk of cardiovascular disease while LDL-cholesterol increases the risk of cardiovascular disease. ${ }^{6}$ Serum lipid is measured as total cholesterol and its fractions; high density lipoprotein (HDL) cholesterol, low density lipoprotein (LDL) cholesterol, very low density lipoprotein (VLDL) cholesterol and triglycerides. Abnormal blood lipid levels, that is high total cholesterol $(>5.0 \mathrm{mmol} / \mathrm{L})$, high levels of triglycerides $(>1.7 \mathrm{mmol} / \mathrm{L})$, high levels of low-density lipoprotein $(>3.0 \mathrm{mmol} / \mathrm{L})$ or low levels of high density lipoprotein cholesterol $(<1.0 \mathrm{mmol} / \mathrm{L})$ men, $(<1.2 \mathrm{mmol} / \mathrm{L})$ women all increase the risk of heart disease and stroke. ${ }^{6}$

The aim of this study was to determine the prevalence of obesity using the measure of body mass index (BMI) and abnormal lipid level and to determine if there is any association between obesity and abnormal lipid level among adults in Ogbomoso, Nigeria.

\section{Study area}

Ogbomoso is located about $100 \mathrm{~km}$ north of Ibadan, the Oyo State capital in Southwest Nigeria. The indigenous people are from the Yoruba ethnic group. The majority of them engage in farming or trading. There are two degree- awarding institutions in Ogbomoso (Ladoke Akintola University of Technology and The Nigerian Baptist Theological Seminary) which attract people from other ethnic groups into the town. A government owned general hospital, a Baptist mission hospital, a few Primary Health Care centres and an increasing number of private hospitals meet the health needs of the people.

\section{Methods}

Approval was obtained from the Ethics Committee of the Baptist Medical Centre, Ogbomoso before the commencement of the study. The study was conducted at the medical out-patients' clinic between January, 2008 and July, 2008. Informed consent was also obtained from the subjects before their enrollment to participate in the study.

A cross sectional descriptive survey was used. Subjects aged 18 years and older who gave consent for the study were recruited. Pregnant women, women in the puerperium (day of delivery to 6weeks post delivery), patients with ascites and intrabdominal masses determined through history and physical examination were excluded from the study. A systematic sampling method was used to select the subjects. The list of patients who were registered each day to see the doctor at the medical out-patients' clinic was taken as a sample frame, and from a review of records, an average of 100 patients were estimated to attend the medical outpatient clinic per day during the period of the study. A sampling fraction of 10 was chosen and a simple random sampling was done to pick the first subject from the first ten patients as the starting number of the systematic sampling technique, subsequent selections were every 10 th registered patient on the register. An identification sticker was placed on all selected subjects' record cards from the records office, where the sampling was done and sent to a designated consulting office for the study.

The selected subjects were screened and those who met the inclusion criteria were recruited for the study after an informed consent was sought and obtained. An identification sticker was left on all selected subjects' cards until the study was over to avoid a repeat selection.

A pre-tested questionnaire was administered by the researcher to obtain the following information: age, sex, marital status, ethnic group, religion, nationality, occupation, educational status, physical activity and family eating habits.

The weight of all the subjects was measured in kilogrammes using the Healthometer scale made by Continental Scale Corporation, USA to the nearest single decimal. The height was determined in metres using the Stadiometer scale to the nearest single decimal. The weight and height were measured with the subjects in light clothing and without shoes. Body mass index (BMI) was calculated as weight $(\mathrm{kg})$ divided by height squared (m2). Obesity was defined as body mass index (BMI) e" $30 \mathrm{~kg} / \mathrm{m}^{2}$ and overweight as $25 \mathrm{~kg} / \mathrm{m}^{2}$ d" BMI $<30 \mathrm{~kg} / \mathrm{m}^{2}$.

The subjects were requested to fast overnight. Blood sample was obtained in the morning after a 12-14hour fast. The blood sample was put in a lithium heparin bottle.

The blood was centrifuged (at 3000rpm, for 10min) about 30 minutes after, and stored at $4^{\circ} \mathrm{c}$ in plain plastic bottles overnight if analysis was not done the same day. The estimation of total cholesterol, HDLcholesterol and triglycerides were done using the colorimetric method. All the analyses were done by a qualified Laboratory Scientist. The

LDL-cholesterol was calculated using the formula. ${ }^{8}$ LDL $=$ Total cholesterol-(HDL + Triglycerides $) / 2.2$ 
Abnormal lipid level was defined by the presence of one or more than one abnormal serum lipid concentration. ${ }^{9}$

The subjects who engaged in leisure time physical activity (walking, fitness training and sports) for greater than or equal to three times per week of thirty minutes per occasion were classified as physically active. ${ }^{10}$

Subjects' diets were classified as 'high calorie' or 'low calorie' diets according to their response to the question asked them to list 5 types of food they ate most in the order of preference and their consumption of fast foods/snacks. Those who had mainly refined carbohydrate and fatty foods including preference for fast foods were classified as having high calorie diet. While those who ate less of refined carbohydrate and fatty meals, and added vegetables and fruits as part of the food they ate most, were classified as having low calorie diets.

The subjects were placed into one of the five social classes based on their occupation using the Registrar General's Scale of social classes. ${ }^{11}$

Class 1: Professional e.g. Lawyer, Doctor, Accountant.

Class 2: Intermediate e.g. Teacher, Nurse, Manager. Class 3N: Skilled non-manual e.g. Typist, Shop assistant, telephone operators.
Class 3M: Skilled manual e.g. Miner, Bus-driver, Cook, artisans.

Class 4: Partly skilled (manual) e.g. Farm worker, Bus conductor.

Class 5: Unskilled e.g. Cleaner, Labourer.

Data were analyzed by computer using the statistical package for social sciences, version 13. (SPSS 13). Means and standard deviations were calculated. Pearson's Chi square test was performed to assess the relationship between obesity, abnormal lipid level, physical activity and diet. P-value of $<0.05$ was set as level of statistical significance.

\section{Results}

A total of 400 subjects aged 18 years and older were recruited for the study. The mean age of the subjects was $48.65 \pm 16.57$ years and there were more female subjects $(55.25 \%)$ than male subjects $(44.75 \%)$. The overall prevalence of obesity was $14.75 \%$.

Obesity increased with age up to the age group 4049 years after which it declined. The mean BMI among the subjects was $24.60 \pm 5.43 \mathrm{Kg} / \mathrm{m} 2(23.15$ $\pm 4.18 \mathrm{Kg} / \mathrm{m} 2$ for males and $25.93 \pm 5.99 \mathrm{Kg} / \mathrm{m} 2$ for females). The prevalence of obesity among the males was $8.9 \%$ while among the females it was $19.5 \% \mathrm{p}<0.05$ (table 1).

Table 1: the association between sex, obesity, physical activity and abnormal lipid level

\begin{tabular}{|c|c|c|c|c|c|}
\hline & Male & Female & Total & $\mathrm{X} 2$ & P-value \\
\hline & n $(\%)$ & n $(\%)$ & $\mathrm{n}(\%)$ & & \\
\hline \multicolumn{6}{|c|}{ BMI obesity } \\
\hline Normal & $126(70.4)$ & $115(52.0)$ & $241(60.2)$ & & \\
\hline Overweight & $37(20.7)$ & $63(28.5)$ & $100(25.0)$ & 15.378 & 0.000 \\
\hline Obese & $16(8.9)$ & $43(19.5)$ & $59(14.8)$ & & \\
\hline Total (n) & $179(100.0)$ & $221(100.0)$ & $400(100.0)$ & & \\
\hline \multicolumn{6}{|c|}{ Physical activity } \\
\hline Active & $88(49.2)$ & $83(37.6)$ & $171(42.7)$ & & \\
\hline Inactive & $91(50.8)$ & $138(62.4)$ & $229(57.3)$ & 5.442 & 0.020 \\
\hline Total (n) & $179(100.0)$ & $221(100.0)$ & $400(100.0)$ & & \\
\hline \multicolumn{6}{|c|}{ abnormal lipid } \\
\hline normal & $131(73.2)$ & $155(70.1)$ & $286(71.5)$ & & \\
\hline abnormal & $48(26.8)$ & $66(29.9)$ & $114(28.5)$ & 0.451 & 0.502 \\
\hline $\operatorname{Total}(\mathrm{n})$ & $179(100.0)$ & $221(100.0)$ & $400(100.0)$ & & \\
\hline
\end{tabular}


The prevalence of physical inactivity among the subjects was $57.3 \%$ (62.4\% for females and $50.8 \%$ for males, $\mathrm{p}<0.05$ ) (table 1). Among the subjects who were obese, $66.1 \%(p>0.05)$ of them were physically inactive (table 2). The overwhelming majority of the subjects who were obese $(88.1 \%)$ preferred to consume high calorie diet $(\mathrm{p}>0.05)$ (table 2 ). More than one-half of the subjects who were obese $(59.3 \%)$ were from social class $3 \mathrm{~N}(\mathrm{P}<0.05)$ (table 2).

The overall prevalence of abnormal lipid levels was $28.5 \%$. The prevalence of abnormal lipid levels among the male was $26.8 \%$ while it was $29.9 \%$ among the female. The prevalence of abnormal lipid levels among the subjects who were obese was $40.7 \%$ $(\mathrm{p}<0.05)$.

Table 2: The association between obesity, physical activity, diet, social class and abnormal lipid level

\begin{tabular}{|c|c|c|c|c|c|c|c|c|}
\hline & Normal & Overweigh & & & ese & Total & $\mathrm{x} 2$ & p-value \\
\hline & n $(\%)$ & n $(\%)$ & $\mathrm{n}$ & $(\%)$ & n $(\%$ & & & \\
\hline Physical act & & & & & & & & \\
\hline Active & $107(44.4)$ & $44(44.0)$ & & & 33.9) & $171(42.7)$ & & \\
\hline Inactive & $134(55.6)$ & $56(56.0)$ & & & 66.1) & $229(57.3)$ & 2.220 & 0.330 \\
\hline Total (n) & $241(100.0)$ & $100(100.0)$ & & & $100.0)$ & $400(100.0)$ & & \\
\hline Diets & & & & & & & & \\
\hline High calorie & 216(89.6) & $86(86.0)$ & & & 88.1) & $354(88.5)$ & & \\
\hline Low calorie & $25(10.4)$ & $14(14.6)$ & & & 1.9) & $46(11.5)$ & 1.577 & 0.813 \\
\hline Total (n) & 241(100.0) & $100(100.0)$ & & & 100.0) & $400(100.0)$ & & \\
\hline Social class & & & & & & & & \\
\hline Class 1 & $3(1.2)$ & $1(1.0)$ & & 0( & & $4(1.0)$ & & \\
\hline Class 2 & 48(19.9) & $28(28.0)$ & & & 18.6) & $87(21.8)$ & & \\
\hline Class 3n & $85(35.3)$ & $51(51.0)$ & & & $59.3)$ & $171(42.8)$ & & \\
\hline Class 3m & 13(5.4) & $5(5.0)$ & & $4(C$ & & $22(5.5)$ & 31.321 & 0.001 \\
\hline Class 4 & $43(17.8)$ & $5(5.0)$ & & $2(3$ & & $50(12.5)$ & & \\
\hline Class 5 & $49(20.3)$ & $10(10.0)$ & & & 1.9) & $66(16.5)$ & & \\
\hline Total (n) & $241(100.0)$ & $100(100.0)$ & & & 100.0) & $400(100.0)$ & & \\
\hline Abnormal li & & & & & & & & \\
\hline Normal & $184(76.3)$ & $67(67.0)$ & & & 59.3) & $286(71.5)$ & & \\
\hline Abnormal & $139(57.7)$ & $33(33.0)$ & & & 40.7) & $114(28.5)$ & 8.068 & 0.018 \\
\hline Total (n) & $241(100.0)$ & $100(100.0)$ & & & $(100.0)$ & $400(10$ & $00.0)$ & \\
\hline
\end{tabular}

$\mathrm{X}^{2}=$ chi square ()$=$ percentage $=\mathrm{n} \div \mathrm{n} \times 100$

\section{Discussion}

It was discovered from this study that obesity increased with age up to age group 40-49years after which it declined. This is similar to what was found in Rivers State, Nigeria by Siminialayi, EmemChioma and Dapper ${ }^{12}$ where they found that obesity was more common among subjects older than 40 years. The prevalence of obesity among our subjects was $14.75 \%$. The prevalence of obesity found in this study is comparable with $16.3 \%$ found in Okrika, Rivers State, Nigeria by Siminialayi, Emem-Chioma and Dapper. ${ }^{12}$

The prevalence of obesity among the males was $8.9 \%$ while it was $19.5 \%$ among the female. The high prevalence of physical inactivity among the female subjects is one of the factors that may be responsible for the high prevalence of obesity found among the female subjects in this study. This is supported by the findings of Kruger, Venter, Vorster and Margetts ${ }^{13}$ in the North West Province, South Africa where they investigated the association between measures and determinants of obesity in African women. They found that physical inactivity showed the strongest association with measures of obesity in their study. The fact that more than one-half $(53.3 \%)$ of the subjects who were obese were traders $(\mathrm{p}<0.05)$ and that the female subjects constituted the 
overwhelming majority $(82.5 \%)$ of the subjects who were traders $(\mathrm{p}<0.05)$ is another reason for the high prevalence of obesity found among the female subjects. Most traders in Ogbomoso spend most of their time sitting down in their shops and engaging in predominantly sedentary activities. This strong association between obesity and trading was also supported by the findings of Afolabi, Addo and Sonibare ${ }^{14}$ in their study in nearby Abeokuta, Ogun State, Nigeria and physical inactivity was the reason given for their findings.

In addition, consumption of high calorie diets is one of the major contributory factors to the development of obesity and this has been corroborated by this study where the majority of the subjects who were obese $(88.1 \%)$ preferred high calorie diet. However, contrary to the findings of many studies ${ }^{15,16}$ where obesity was strongly associated with high socio-economic status, more than one half of the subjects who were obese $(59.3 \%)$ were from the social class $3 \mathrm{~N}$. This observation may be as a result of low representation of the subjects from social class 1 in Ogbomoso where they constituted only $1 \%$ of the total study population. Furthermore, it was discovered that the overall prevalence of abnormal lipid levels was $28.5 \%$. This is at variance with the findings of Yao, Frommlet, Zhou, Zu, Wang, Yan et $\mathrm{al}^{7}$ in Xinjiang, China where they found prevalence of $53.5 \%$ in the general population. The reference value used in this study is the one used in Europe, ${ }^{6}$ so that may be one of the reasons responsible for this finding.

This is also supported by other studies that reported relatively lower levels of lipid profile in Africans than their Caucasian counterparts. ${ }^{17,18,19}$ Among the subjects who were obese, $40.7 \%$ of them had abnormal lipid levels.

\section{Conclusion}

The findings from this study have suggested that obesity in this environment is particularly significant among females and is associated with abnormal lipid level. Therefore, there is need to promote lifestyle modification in Ogbomoso in order to retard the increasing prevalence of obesity and its associated complications.

The measurement of BMI should be made a routine procedure in the health care facilities. This will help in the early detection of patients who are overweight or obese before they develop complications associated with obesity.

\section{References}

1 Pasquet P, Temgoua LS, Melaman-Sego F, Froment A, Rikong-Adie H. Prevalence of overweight and obesity for urban adults in Cameroon. Ann Hum Biol 2003;30(5):551-62.

2 World Health Organization. Global strategy on diet, physical activity and health. (Online). 2004. (cited 2008 Oct 22); Available from: URL:http:/ /www.who.int/dietphysicalactivity/publications/ facts/en/ index.html

3 World Health Organization. Obesity and overweight. (Online). 2006 Sept (cited 2008 Dec 22); Available from: URL: http://www.who.int/ mediacentre/factsheets/fs311/en/

4 The European Food Information Council. Obesity and overweight. (Online). 2006. (cited 2008 Oct 22); Available from: URL: http:// www.eufic.org/article/en/expid/basics-obesityoverweight/

5 Yasein N, Ahmad M, Matrook F, Nasir L, Froelicher ES. Metabolic syndrome in patients with hypertension attending a family practice clinic in Jordan. East Mediterr Health J. 2010;16(4):37580.

6 World Heart Federation. Cardiovascular disease risk factors - cholesterol. (Online). 2005. (cited 2008 Oct 22); Available from: URL: http:// www.world-heart-federation.org/cardiovascular health/cardiovascular-disease-risk-factors/ cholesterol/

7 Araoye MO. Research Methodology with Statistics for health and social science. $1^{\text {st }}$ ed. Ilorin: Nathadex; 2003. p. 115-129.

8 Lawrence MT, Stephen JM, Maxin AP. Current medical diagnosis and treatment. $43^{\text {rd }}$ ed. New York: Lange Medical Books/ McGraw-Hill; 2004. p. 348.

9 Yao XG, Frommlet F, Zhou L, Zu F, Wang H, Yan $Z$ et al. The prevalence of hypertension, obesity and dyslipidemia in individuals of over 30 years of age belonging to minorities from the pasture area of Xinjiang. BMC Public Health 2010; 10:91

10 Physical Activity and Health: A report of the Surgeon General. Washington DC: US department of health and human services. (Online) 2008 Jan. (cited 2008 Oct 17); Available from : URL http://www.surgeongeneral.gov/ library/disabilities/calltoaction/ whatitmeanstoyou.html\#choose 
11 Social Research Update. (Online). 1995 July. (cited 2008 Oct 17); Available from:URL http:// sru.soc.surrey.ac.uk/SRU9.html

12 Siminialayi IM, Emem-Chioma PC, Dapper DV. The prevalence of obesity as indicated by BMI and waist circumference among Nigerian adults attending Family Medicine clinics as outpatients in Rivers State. Niger J Med 2008;17(3):340-5.

13 Margetts BM, Kruger HS, Venter CS, Vorster $\mathrm{HH}$. Physical inactivity is the major determinant of obesity in black women in the North West Province, South Africa the THUSA study. Transition and health during urbanization of South Africa. Nutrition 2002;18(5):422-7.

14 Afolabi AO, Addo AA, Sonibare MA. Activity pattern, energy intake and obesity among Nigerian urban market women. Int J Food Sci Nutr 2004;55(2):85-90.
15 Leopold F, Etienne M, Beverley B, André-Pascal $\mathrm{K}$, Paschal A, Nigel U et al. Association between socioeconomic status and adiposity in urban Cameroon. Int J Epid 2006;35(1):105-111.

16 Goyal RK, Shah VN, Saboo BD, Phatak SR, Shah NN, Gohel MC et al. Prevalence of overweight and obesity in Indian adolescent school going children: its relationship with socioeconomic status and associated lifestyle factors. J Assoc Physicians India. 2010;58:151-8.

17 Glew RH, William M, Conn CA, Cadena SM, Crossey $\mathrm{M}$, Okolo SN. Cardiovascular disease risk factors and diet of Fulani pastoralists of Northern Nigeria. Am Jclinical Nutrition 2001;74(6):730-6

18 Jarikre AE, Dim DC, Ajuluchukwu JNA. Plasma lipids in Nigerian hypertensive: the gender factor. Nigerian Quarterly Journal of Hospital Medicine 1996; 6:281-298.

19 Adams -Cambel L.L., Nwankwo M.U., Omene J.A., Ukoli F.A.,Young MP., Haile GT et al. Assessment of cardiovascular risk factors in Nigerian students. Arteriosclerosis 1988;8: 793-796. 